\title{
Studies on the Intracellular Localization of Acetyl-CoA Carboxylase
}

\author{
Math J . H. Geelen, ${ }^{* 1}$ Caspaar Bijleveld,* Guillermo Velasco,† \\ Ronald J . A. Wanders,ł and Manuel Guzmán† \\ *Laboratory of Veterinary Biochemistry and Institute of Biomembranes, Utrecht University, 3508 TD Utrecht, \\ The Netherlands; †Department of Biochemistry and Mol ecular Biology I, Faculty of Biology, Complutense University, \\ 28040-Madrid, Spain; and ¥Emma Children's Hospital, Amsterdam University, 1100 DD Amsterdam, The Netherlands
}

The present work was performed to identify the subcellular localization of hepatic acetyl-CoA carboxylase (ACC). Cellular organelles involved in fatty acid oxidation that contain a malonyl-CoA sensitive carnitine palmitoyltransferase (CPT) activity or that are linked to the control of this activity were analysed for the presence of ACC. No significant amount of ACC was observed in the mitochondrial fraction prepared from isolated rat hepatocytes. F urthermore, no association of ACC activity and mass with isolated hepatic peroxisomes could be detected. In cubation of isolated hepatocytes with compounds known to affect the integrity of the cytoskeleton like okadaic acid or taxol indicates that ACC is associated with this subcellular structure of the hepatocyte. Such association may allow for efficient regulation of CPT activity and thus of fatty acid oxidation. () 1997 Academic Press

Depending on the physiological state of the animal, the liver is a tissue that can either exhibit high rates of fatty acid biosynthesis or high rates of fatty acid oxidation. Control of the activity of acetyl-CoA carboxylase (ACC) is of special interest in this respect because the product of ACC, malonyl-CoA, is not only a substrate for the cytosolic process of long-chain fatty acid synthesis but is also an inhibitor of the activity of carnitine palmitoyltransferase (CPT), an important pacesetting enzyme of long-chain fatty acid oxidation (1). As a matter of fact, malonyl-CoA sensitive CPT activity is present both in mitochondrial outer membranes (CPT-I) (2) and in the peroxisomal matrix (3).

Given the functions of malonyl-CoA in or on different organelles of the cell, the enzyme responsible for its production, ACC, may be compartmentalized as well.

\footnotetext{
${ }^{1}$ To whom correspondence should be addressed.
}

Sinceits original discovery as a solubleenzyme (4) AAC has been assumed to be located in the cytoplasm. Earlier work concluded that the activity of the enzyme was not associated with subcellular particles (5), but later reports indicated that activity of ACC could be detected in high speed precipitates of rat-liver homogenates (68) and in a so-called mitochondrial fraction of such homogenates $(9,10)$. Furthermore, permeabilization of isolated hepatocytes with digitonin also suggested association of the enzyme with some kind of intracellular structure (11).

These conclusions have relied on assays of enzyme activity in cellular fractions (6-11) and on measurement of ACC mass by a technique employing the binding of radiolabelled avidin $(9,10)$. Both procedures are prone to error. The measurement of the activity of ACC is subject to modifi cation of that activity by several factors (12-15), and the avidin binding method is sensitive to interference by other biotin-containing proteins competing for labelled avidin (16). Therefore, the determination of subcellular distribution on the basis of avidin binding or enzyme activity is difficult to interpret.

The availability of ACC antibodies (17) and the technique of permeabilizing isolated hepa tocytes with digitonin (15) has permitted to re-address the issue of localization of ACC and to cir cumvent some of the methodological problems.

\section{MATERIALS AND METHODS}

Male Wistar rats ( $250-300 \mathrm{~g})$ which had free access to food and
water were used throughout in this study. Hepatocytes were isolated
and incubated as described in (18). Acetyl-CoA carboxylase activity,
isoform distribution and mass were determined in isolated hepatic
mitochondria, isolated hepatic peroxisomes or in digitonin-perme-
abilized hepatocytes. For isolation of mitochondria from liver tissue,
the procedure described by Roman-Lopez et al. (19) was followed.
Mitochondria from hepatocytes were isolated by homogenizing cells
(4-6 mg of protein) with a loose-fitting Dounce homogenizer in a low 
ionic strength, iso-osmotic medium consisting of $0.3 \mathrm{M}$ mannitol and $2 \mathrm{mM}$ Hepes $\mathrm{pH} 7.4$ in the presence of a proteinase inhibitor mixture (17). The homogenate was centrifuged at $1500 \times \mathrm{g}$ for $2 \mathrm{~min}$. The pellet was discarded and the supernatant centrifuged for $2 \mathrm{~min}$ at $16.000 \times \mathrm{g}$. The resulting supernatant was termed the cytosolic fraction. The pellet was washed once by resuspension in the low ionic strength medium and recentrifugation at $16.000 \times \mathrm{g}$. The resuspended final pellet was termed the mitochondrial fraction. Peroxisomes were isolated from animals fed a standard pelleted diet supplemented with $1 \%$ di(2-ethylhexyl)phtalate in order to proliferate the peroxisomal compartment (20). Treatment of animals and isolation of peroxisomes was performed as in (20). All homogenizing steps and subsequent procedures were performed at $4^{\circ} \mathrm{C}$. The isolated fractions were snap frozen in liquid nitrogen and stored at $-20^{\circ} \mathrm{C}$. To determine the amount of ACC retained in the cell ghosts following incubation of the intact hepatocytes with different cellular effectors, the isolated cells were permeabilized and thoroughly washed prior to harvesting the cell ghosts. Thus, $1.0 \mathrm{ml}$ of hepatocyte suspension was permeabilized with digitonin (ca. $60 \mu \mathrm{g}$ per mg cell protein) dissolved in a medium containing $50 \mathrm{mM}$ Hepes ( $\mathrm{pH} 7.5), 0.25 \mathrm{M}$ mannitol, $5 \mathrm{mM}$ 2-mercaptoethanol and a proteinase inhibitor mixture as in (17). The resulting mix of cells and permeabilizing medium was gently shaken for $5 \mathrm{~s}$. and rapidly diluted by transfer to tubes containing $40 \mathrm{ml}$ of ice-cold medium without digitonin. Cell ghosts were sedimented by centrifugation at $350 \mathrm{~g}$ for $15 \mathrm{~s}$, and pellets were taken up in $1.0 \mathrm{ml}$ ice-cold medium containing $50 \mu$ l of the proteinase inhibitor mixture. The resulting suspensions of cell ghosts were kept at $-80^{\circ} \mathrm{C}$ till mass measurements were performed. Determination of total ACC mass retained in cell ghosts following digitonin treatment or associated either with isolated mitochondria or peroxisomes, was performed with an ELISA assay essentially as described by I verson et al. (21) employing a primary antiserum against rat-liver ACC (17). The distribution of isoforms was determined using immunopre cipitation, SDS/PAGE, immunoblotting and auto radiography as in (17). Activities of ACC and fatty acid synthase were monitored exactly as described before $(15,17)$. Sources of chemicals as in (17).

\section{RESULTS}

The present study was undertaken to identify the subcellular localization of ACC. In order to investigate a possible association of ACC with mitochondria - as suggested by Allred and co-workers $(9,10)$ - mitochondria were prepared from isolated hepatocytes. With such a preparation less mechanical force is required to liberate mitochondria as compared to whole tissue as the star ting material. Mechanical interference with an association of ACC and mitochondria was further kept to a minimum by using a loose-fitting Dounce homogenizer. To interfere as little as possible with potential electrostatic interactions between enzyme and organelle, a low ionic strength medium was chosen for isolation of the subcellular fractions. In addition, the whole isolation procedure-including subcellular fractionation by centrifugation - was aimed at speed rather than at recovery. Activity measurements for ACC of the resulting subcellular fractions could not be performed because of the presence of malonyl-CoA decarboxylase in mitochondria. The latter enzyme interferes with the assay for ACC activity (15). The subcellular fractions were analysed by SDS gel electrophoresis for the presence of the 265-kDa and 280-kDa isoforms of ACC

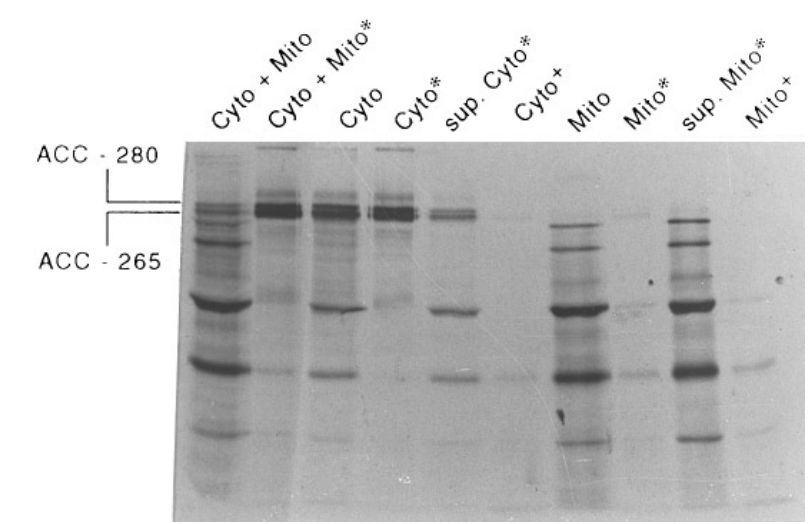

FIG. 1. Acetyl-CoA carboxylase (ACC) analysis of subcellular fractions of hepatocytes from normally fed rats by SDS gel electrophoresis. Cytosolic (Cyto) and mitochondrial (Mito) fractions obtained from isolated hepatocytes (see Materials and Methods) were analysed for the presence of the ACC-265 and ACC-280. A sample equivalent to $100 \mu \mathrm{g}$ of protein of each fraction was loaded to the lanes as indicated. Following labeling with $\left[{ }^{35} \mathrm{~S}\right]$ streptavidin, SDS/ PAGE and transfer to nitrocellulose, the biotin-containing proteins were visualized by autoradiography. ${ }^{*}$ I ndicates that the immunoprecipitate with a primary antiserum against rat-liver ACC was loaded in that lane; +indicates that an immunoprecipitate with a pre-immune serum was loaded; the prefix sup. indicates that the supernatant of the immunoprecipitate was loaded.

(ACC-265 and ACC-280, respectively). The two isoforms have been suggested to play different biological roles. In particular, ACC-280 is of interest in this respect because it might be involved in the synthesis of malonyl-CoA for inhibition of CPT-I $(22,23)$. Since the latter enzyme has a mitochondrial localization (24), an association of ACC-280 with mitochondria would be feasible. Fig. 1 shows the analysis of the presence of ACC isoforms in the subcellular fractions from isolated hepatocytes. The results do not reveal a mitochondrial Iocalization of either of the two ACC isoforms. In an attempt to spare potential hydrophobic interactions between ACC and mitochondria, the latter organelles were also prepared from isolated hepatocytes in a high ionic strength medium $(0.9 \% \mathrm{NaCl}$ and $20 \mathrm{mM}$ Tris $\mathrm{pH}$ 7.4) exactly as described for the low ionic strength medium. Also in this case no association of any of the ACC-isoforms with the mitochondrial fraction was apparent (data not shown). The analysis of the presence of ACC-isoforms in the mitochondrial fraction was repeated with two different primary antisera also raised against rat-liver ACC. The results were identical to those presented in Fig. 1. (data not shown). The analysis of the presence of ACC isoforms was also performed on subcellular fractions of rat-liver cells from animals in different nutritional states, i.e. starved for $48 \mathrm{~h}$ and starved for $48 \mathrm{~h}$ fol lowed by refeeding a carbohydraterich, fat-poor diet for $48 \mathrm{~h}$. No significant mass of either ACC isoform was observed in the mitochondrial fraction in any of the nutritional states (data not shown). 


\section{TABLE 1}

Activities of Phosphoglucoisomerase (PGI), Catalase, Fatty Acid Synthase (FAS), and Acetyl-CoA Carbozylase (ACC) in Post-Nuclear Supernatant (PNS) and in Isolated Peroxisomes from Liver of Control and Di(2-ethylhexyl)phtalate (DEHP)-Treated Rats

\begin{tabular}{|c|c|c|c|c|}
\hline \multirow[b]{2}{*}{ Enzyme } & \multicolumn{2}{|c|}{ PNS } & \multicolumn{2}{|c|}{ Peroxisomes } \\
\hline & Control & DEHP & Control & DEHP \\
\hline \multicolumn{5}{|c|}{ ( $\mu \mathrm{mol} / \mathrm{min} / \mathrm{mg}$ protein) } \\
\hline $\begin{array}{l}\text { Catalase } \\
\text { PGI }\end{array}$ & $\begin{array}{l}0.83 \\
0.55\end{array}$ & $\begin{array}{l}0.97 \\
0.39\end{array}$ & $\begin{array}{l}10.6 \\
0.013\end{array}$ & $\begin{array}{l}6.64 \\
0.023\end{array}$ \\
\hline \multicolumn{5}{|c|}{ (nmol/min/mg protein) } \\
\hline $\begin{array}{l}\text { FAS } \\
\text { ACC }\end{array}$ & $\begin{array}{l}1.88 \pm 0.11 \\
0.34 \pm 0.03\end{array}$ & $\begin{array}{l}1.14 \pm 0.03 \\
0.42 \pm 0.01\end{array}$ & $\begin{array}{l}\text { n.d. } \\
\text { n.d. }\end{array}$ & $\begin{array}{l}\text { n.d. } \\
\text { n.d. }\end{array}$ \\
\hline
\end{tabular}

Note PGI and catalase are marker enzymes for cytosol and peroxisomes, respectively. Data represent means of two control and two DEHP-treated animals. n.d., nondetectable.

Hepatic peroxisomes exhibit CPT activity that is sensitive to inhibition by malonyl-CoA $(3,25)$. To study a possible association of ACC with this organelle, peroxisomes were isolated from liver tissue obtained from rats treated with di(2-ethylhexyl)phtalate (DEHP), a proliferator of the peroxisomal compartment (20). The data in Table 1 indicate that there is no association of ACC activity with peroxisomes from both control and DE HP-treated animals. Likewise, no significant association of ACC to peroxisomes was observed on the basis of measurements of enzyme mass (data not shown).

Our recent observation that cytoskel etal components are most likely involved in the control of the activity of CPT-I (26) prompted us to consider a cytoskeletal localization of ACC, since the latter enzyme is pivotal in the control of CPT-I activity (1). To analyse a potential association of ACC with the cytoskeleton, isolated hepatocytes were incubated with various compounds known to affect cytoskeletal integrity. Subsequently, cells were permeabilized by short-term treatment with digitonin followed by rapid removal of released cytosolic proteins including ACC. In this approach, ACC associated with a subcellular structure will be sedimented. The resulting pellet was used to determine ACC mass. The possibility of an association between ACC and cytoskeletal components was tested by the use of okadaic acid (OA), taxol and colchicine. OA has been shown to disrupt the cytoskeleton of hepatocytes (27). Taxol binds to tubulin and stabilizes microtubules, preventing the disassembly of microtubules in a very efficient fashion (28). The polymeric state of microtubules can be dissociated by colchicine (29). The data of Table 2 show that incubation of hepatocytes with OA resulted in the release of substantially more ACC than in control cells. Interestingly, the OA-induced effect was completely abolished by pretreating the hepatocytes with taxol (Table 2). Likewise, pretreatment of the cells with $\mathrm{KN}-62$, a specific inhibitor of $\mathrm{Ca}^{2+} / \mathrm{cal}-$ modulin-dependent protein kinase II, also prevented the OA-induced release of hepatic ACC. 5-Aminoimidazole-4-carboxamide ribonucleoside (AICAR), a specific activator of 5'-AMP-activated protein kinase, was without effect on the retention of ACC mass in cell ghosts (Table 2). I ncubation of hepatocytes with colchicine did not affect the release of ACC from digitonin-permeabilized cells either. The data obtained with amyloglucosidase (Table 2) suggest that glycogen granules represent a subcellular structure capable of binding ACC. To determine whether the two ACC isoforms will differentially release upon permeabilization, the cell ghosts were also analysed for the presence of ACC-265 and ACC-280. However, irrespective of the incubation condition, the ratio of ACC-265/ACC-280 was identical, i.e. ACC-280 was always about one third of the total ACC mass (data not shown).

\section{DISCUSSION}

Several studies performed by others (6-10) as well as by our group (11) led to the suggestion of association of

\section{TABLE 2}

Mass Measurements of Acetyl-CoA Carboxylase Retained in Digitonin-Permeabilized Rat Hepatocytes

\begin{tabular}{lc}
\hline \multicolumn{1}{c}{ Additions } & $\begin{array}{c}\text { Percentage of total ACC mass } \\
\text { retained in cell ghosts }\end{array}$ \\
\hline Control & $53.2 \pm 18.0$ \\
OA & $20.6 \pm 8.0^{*}$ \\
Taxol + OA & $55.5 \pm 6.6$ \\
KN-62 + OA & $48.5 \pm 10.5$ \\
AlCAR & $46.0 \pm 19.5$ \\
Colchicine & $64.5 \pm 8.7$ \\
Taxol + colchicine $_{\text {Control }}^{\text {a }}$ & $67.9 \pm 1.0$ \\
Control + amyloglucosidase $^{\mathrm{a}}$ & $15.8 \pm 2.8$ \\
\hline
\end{tabular}

Note Hepatocytes were preincubated for 20 min with or without $10 \mu \mathrm{M}$ taxol or $30 \mu \mathrm{M} \mathrm{KN}-62$. Incubations were continued for 15 additional min with or without $0.5 \mathrm{mM}$ 5-aminoimidazole-4-carboxamide ribonucleoside (AICAR), $0.5 \mu \mathrm{M}$ okadaic acid (OA) or $0.1 \mathrm{mM}$ colchicine. Subsequently, cell ghosts were prepared as described in Materials and Methods. ACC retained in the cell ghosts was quantified by avidin-based ELISA analysis using as the probing antibody a primary antiserum against rat-liver ACC (17).

a These results are from two sets of cell ghosts of control cells resuspended and incubated for 15 additional min with or without 50 $\mathrm{U}$ amyloglucosidase. Results represent the mean \pm S.D. of 3 different hepatocyte preparations. The amount of ACC present in intact hepatocytes was set at $100 \%$. Values of OA are significantly different $(P<0.01)$ versus its control using the Student t test. This also applies to amyloglucosidase $(\mathrm{P}<0.01)$ versus its control. 
ACC to a subcellular organelle. However, after careful isolation, no association of ACC with either mitochondria or peroxisomes could be observed in the present study. Nonetheless, in the intact cell an association may exist that is not firm so that the enzyme can escape into the supernatant during the biochemical preparation procedure. The present approach of using the technique of permeabilizing isolated hepatocytes rather than homogenizing the cells revealed an association of ACC with the cytoskeleton. The implication of this cytoskeletal connection of both ACC (this study) and CPT-I (26) is that it allows for an efficient regulation of fatty acid oxidation through malonyl-CoA-induced changes in CPT-I activity. Furthermore, the different digitonin-release-pattern of ACC following incubation of hepatocytes with OA as compared to the control situation raises the possibility that ACC may translocate from one compartment to another, depending on the situation of the cell, and thus efficiently control the activity of CPT-I.

It could be argued that the release pattern of ACC following digitonin permeabilization is a reflection of its state of aggregation and that OA by favoring the monomeric state of the enzyme would cause less ACC to be retained by the cell ghosts. However, the identical ACC release pattern following incubation of hepatocytes with insulin or glucagon - putative affectors of the aggregation state of ACC (30)-is not in line with this reasoning (unpublished data of the authors). The inability of AICAR to alter ACC retention by cell ghosts may also indicate that there is no relation between phosphorylation - at least by 5'-AMP-activated protein kinase-and retention of the enzyme by cell ghosts.

The antagonistic effect of $\mathrm{KN}-62$ and taxol on OAinduced release of $A C C$ is quite similar to the antagonistic effect of the two former compounds on the OAinduced stimulation of CPT-I activity $(26,31)$. Data of KN-62 are of special interest since this compound also prevents quite effectively the OA-induced inhibition of ACC activity as measured in a permeabilized-cell assay (unpublished data of the authors). This implicates $\mathrm{Ca}^{2+}$ /calmodulin-dependent protein kinase II in the control of both ACC and CPT-I and is at odds with the opinion that $5^{\prime}$-AMP-activated protein kinase is the most important-if not unique-protein kinase involved in the control of ACC in intact hepatocytes (32). In addition, phosphorylation of cytoskeletal components-as shown by the effects of $\mathrm{KN}-62$ and $\mathrm{OA}-$ may be required for ACC to be released from its anchoring place on the cytoskeleton. Interestingly, colchicine was without effect just like in the case of CPT-I activity (26) suggesting that specific protein-protein interactions between the two enzymes and cytoskel etal components and not the mere disruption of the cytoskeleton may be involved in the intracellular behavior of the two enzymes and their control.

\section{ACKNOWLEDGMENTS}

These investigations were supported in part by the Netherlands Foundation for Chemical Research (SON) with financial aid from the Netherlands Organization for Scientific Research (NWO) as well as by the Spanish "Comisión Interministerial de Ciencia y Tecnologia (SAF 93/0281)."

\section{REFERENCES}

1. McGarry, J . D., and Foster, D. W. (1980) Annu. Rev. Biochem. 49, 395-420.

2. Murthy, M. S. R., and Pande, S. V. (1987) Proc. Natl. Acad. Sci. USA 84, 378- 382.

3. Derrick, J . P., and Ramsay, R. R. (1989) Biochem. J . 262, 801806.

4. Wakil, S. J ., Titchener, E. B., and Gibson, D. M. (1958) Biochim. Biophys. Acta 29, 225-226.

5. Wakil, S. J., McLain, L. W., and Warshaw, J . B. (1960) J . Biol. Chem. 235, PC31-PC32.

6. Abraham, S., Lorch, E., and Chaikoff, I. L. (1962) Biochem. Biophys. Res. Commun. 7, 190- 193.

7. Margolis, S. A., and Baum, H. (1966) Arch. Biochem. Biophys. 114, 445- 451.

8. Witters, L. A., Friedman, S. A., and Bacon, G. W. (1981) Proc. Natl. Acad. Sci. USA 78, 3639- 3643.

9. Allred, J . B., Roman-Lopez, C. R., Pope, T. S., and Goodson, J . (1985) Biochem. Biophys. Res. Commun. 129, 453- 460.

10. Roman-Lopez, C. R., Shriver, B.J ., J oseph, C. R., and Allred, J . B. (1989) Biochem. J . 260, 927-930.

11. Bijleveld, C., Vaartjes, W. J ., and Geelen, M. J . H. (1989) Horm. Metab. Res. 21, 602-605.

12. Lane, M. D., and Moss, J . (1971) in Metabolic Pathways (Vogel, H. J., Ed.), Vol. 5, pp. 23-53, Academic Press, New York.

13. Volpe, J . J ., and Vagelos, P. R. (1976) Physiol. Rev. 56, 339- 417.

14. Wakil, S. J ., Stoops, J. K., and J oshi, V. C. (1983) Annu. Rev. Biochem. 52, 537-579.

15. Bijleveld, C., and Geelen, M. J . H. (1987) Biochim. Biophys. Acta 918, 274- 283.

16. Roman-Lopez, C. R., Goodson, J ., and Allred, J . B. (1987) J . Lipid Res. 28, 599- 604.

17. Guzmán, M., Bijleveld, C., and Geelen, M. J . H. (1995) Biochem. J. 311, 853-860.

18. Beynen, A. C., Vaartjes, W. J ., and Geelen, M. J . H. (1979) Diabe tes 28, 828-835.

19. Roman-Lopez, C.R., Shriver, B. J ., J oseph, C. R., and Allred, J . B. (1989) Biochem. J . 260, 927-930.

20. Wanders, R. J.A., Romeijn, G.J ., Schutgens, R. B. H., and Tager, J . M. (1989) Biochem. Biophys. Res. Commun. 164, 550555.

21. Iverson, A.J ., Bianchi, A., Nordlund, A.-C., and Witters, L. A. (1990) Biochem. J . 269, 365-371.

22. Bianchi, A., Evans, J . L., Iverson, A. J ., Nordland, A. C., Watts, T. D., and Witters, L. A. (1990) J . Biol. Chem. 265, 1502- 1509.

23. Lopaschuk, G. D., Belke, D. D., Gamble, J ., Itoi, T., and Schönekess, B. O. (1994) Biochim. Biophys. Acta 1213, 263- 276.

24. Guzmán, M., and Geelen, M. J . H. (1993) Biochim. Biophys. Acta 1167, 227- 241. 
25. Guzmán, M., and Geelen, M. J . H. (1992) Biochem. J . 287, 487492.

26. Velasco, G., Sánchez, C., Geelen, M.J.H., and Guzmán, M. (1996) Biochem. Biophys. Res. Commun. 224, 754- 759.

27. Holen, I., Gordon, P. B., and Seglen, P. O. (1993) Eur. J . Biochem. 215, 113- 122.

28. Nogales, E., Grayer Wolf, S., Khan, I. A., Ludueña, R. F., and Downing, K. H. (1995) Nature 375, 424- 427.
29. Timasheff, S. N., and Grisham, L. M. (1980) Annu. Rev. Biochem. 49, 565- 591.

30. Mabrouk, G. M., Helmy, I. M., Thampy, K. G., and Wakil, S.J . (1990) J . Biol. Chem. 265, 6330-6338.

31. Velasco, G., Guzmán, M., Zammit, V. A., and Geelen, M.J.H. (1997) Biochem. J . 321, 211-216.

32. Hardie, D. G. (1992) Biochim. Biophys. Acta 1123, 231- 238. 